\title{
Uma Ação Sinérgica por Direitos Reprodutivos: uma história sem fim'
}

\section{A Synergistic Action towards a Policy of Reproductive Rights: a neverending story}

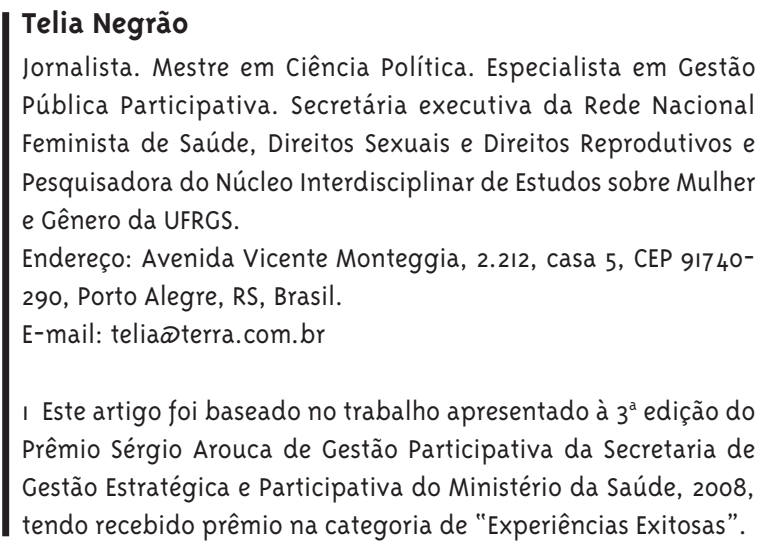

\section{Resumo}

No Brasil, os direitos reprodutivos estão previstos em legislação nacional e normativas do Ministério da Saúde, devendo ser objeto de políticas públicas, e também uma agenda do movimento de mulheres desde os anos 1970. O planejamento familiar integra essas políticas, tendo como base os princípios da não coerção e escolha informada e responsável, implicando em parâmetros éticos. O Conselho Municipal de Saúde de Porto Alegre, mecanismo instituído por lei para exercer o controle social sobre essas políticas, foi instado em 2006 a assegurar os parâmetros éticos e legais quando um programa de implantes hormonais em adolescentes foi autorizado pela prefeitura sem debate no Conselho. A proposta deste artigo é refletir a partir da Ciência Política e do Feminismo sobre as estratégias utilizadas pelo movimento de mulheres para a reversão desse programa, suas alianças e argumentos, bem como as lições aprendidas. Como resultado se obteve a reversão do programa de implantes e o reposionamento do Conselho como órgão deliberativo da política de saúde

Palavras-chave: Direitos reprodutivos; Saúde; Feminismo; Demografia; Controle social; Participação. 


\section{Abstract}

In Brazil, reproductive rights are provided for a national legislation and regulations of the Ministry of Health, should be the object of public policy, and is an agenda of women's movement since 1970 decade. Family planning integrates these policies, based on the principles of non-coercion, informed choice and responsible, resulting in ethical standards. The health council of Porto Alegre, a mechanism established by law to exercise social control over those policies, was asked in 2006 to ensure the ethical and legal parameters when a program of hormone implants in adolescents has been authorized by the city without a debate in the Council. The purpose of this paper is to discuss, from the Political Science and Feminist Theory the strategies used by the feminist movement for the reversal of this program, its alliances and arguments, as well as lessons learned. As a result is has obtained the reversal of the implants program and the deliberative body of the Health Council on health public policy.

Keywords: Reproductive Rights; Health; Feminism; Demography; Social Control; Participation.

\section{Introdução}

Discussões sobre reprodução, anticoncepção, contracepção e planejamento familiar articulam-se há três séculos com desenvolvimento, população, demografia, controle de natalidade (Correa, 2004), influindo nas políticas governamentais. A partir da década de 1980 o movimento de mulheres e feminista também passou a intervir como ator político tendo momentos relevantes como a criação do Programa de Assistência Integral à Saúde da Mulher (PAISM) em 1983 e a Conferência de População e Desenvolvimento, que resultou no Programa de Ação do Cairo (1994). Com a criação do Sistema Único de Saúde e a instituição de mecanismos de controle social das políticas de saúde, o movimento de mulheres busca incluir e politizar os temas da saúde e dos direitos reprodutivos na agenda dos conselhos de saúde, e desta forma ampliar o apoio da sociedade em sua defesa.

Este artigo tem como objetivo relatar e propor a reflexão acerca de uma experiência de ação coletiva compartilhada pelo movimento de mulheres feminista e instâncias de controle social da saúde no município de Porto Alegre nos anos de 2006 a 2007. Seu subtítulo anuncia a existência de desdobramentos em relação aos fatos que serão informados ao final, no entanto o processo analisado mantém, quanto aos seus fundamentos, a mesma relevância. Originalmente elaborado a partir da Ciência Política, este texto foi apresentado em concurso nacional na categoria de experiências exitosas ${ }^{2}$ e foi enriquecido por aportes provenientes de um estudo etnográfico desenvolvido no mesmo período por Jardim (2009), o que permite uma múltipla visão do que se tornou conhecido como "Caso dos Implantes Hormonais de Porto Alegre".

Inicialmente, são relatados o fato e seus desdobramentos em ações caracterizadas ora como advocacy ora como controle social. Em seguida, faz-se uma recuperação histórica da constituição e consolidação dos conceitos de direitos reprodutivos e de integralidade da saúde da mulher no Brasil, sob influência de um cenário internacional, e, por fim,

2 Este artigo foi baseado no trabalho apresentado à 3a edição do Prêmio Sérgio Arouca de Gestão Participativa da Secretaria de Gestão Estratégica e Participativa do Ministério da Saúde, 2008, tendo recebido prêmio na categoria de "Experiências Exitosas". 0 texto original foi elaborado em parceria com Neusa Selma Lyrio Heinzelmann. 
é feita uma reflexão a partir da Ciência Política e do Feminismo. Como nota final, são apresentados os dados de outubro de 2009, momento em que o artefato contraceptivo Implanon estaria perdendo a validade de três anos.

É necessário fazer uma ressalva: este artigo foi elaborado a partir de observação participante impregnada com a vivência jornalística da autora, o que trouxe dificuldades para alcançar o almejado distanciamento acadêmico.

\section{O Caso dos Implantes Hormonais de Porto Alegre: os fatos}

Notícias veiculadas no dia 27 de novembro de 2006 em meios de comunicação nacionais e locais possibilitaram o conhecimento público a respeito do aval da Secretaria Municipal de Saúde de Porto Alegre para que a Organização Não Governamental - Instituto Mulher Consciente - IMC”, em parceria com o Laboratório Organon, desenvolvessem um programa de implantes de contraceptivos hormonais em jovens de 15 a 18 anos, em dez bairros da capital do Rio Grande do Sul.

Transformado em fato midiático, o anúncio foi recebido com entusiasmo pelos meios de comunicação, que noticiaram e reforçaram repetidamente em seus espaços editoriais a sua relevância. $\mathrm{O}$ site G1, da Rede Globo, por exemplo, atualizou o noticiário várias vezes num mesmo dia, dando continuidade por cinco dias consecutivos, inserindo novos argumentos de apoio ao programa municipal, com chamadas variando entre: "Adolescentes gaúchas vão receber implante de anticoncepcionais", "Médicos serão treinados para implantar anticoncepcionais em adolescentes", "Primeiro implante contraceptivo gratuito será feito em 10 dias", "Índice de gravidez na adolescência continua a crescer no Brasil" e "Jovens até 20 anos representam 17,6\% das grávidas em Porto Alegre". Títulos impactantes que, na análise do movimento de mulheres, ocultavam uma política de controle reprodutivo através de parceria público-privada inadequada em diversos aspectos.
Do ponto de vista jurídico, o programa feria a Lei de Planejamento Familiar, a Política Nacional de Direitos Sexuais e Reprodutivos consubstanciados nas Leis 8.080/1990 e 8.142/1990 que criam o SUS e estabelecem o Controle Social, além de aspectos éticos, técnicos e de gestão.

Segundo anunciado na imprensa, dezesseis agrupamentos populacionais situados em dez bairros de Porto Alegre, identificados pelas Unidades Sanitárias do SUS ${ }^{3}$, haviam sido arrolados para receber os 2.500 implantes de etnogestrel, denominado comercialmente de Implanon pelo Laboratório Organon. Aos poucos se revelava que a colocação do artefato hormonal já havia sido iniciada antes mesmo da publicidade, por meio da sensibilização e do cadastramento de adolescentes. A aplicação teve início em dois bairros: o de Navegantes, onde se situa um bolsão de pobreza representado por uma favela, com registros persistentes de exploração sexual de meninas, filhas de trabalhadores papeleiros; e na Restinga, situada na Zona Sul, com cerca de 200 mil habitantes. Entre as concentrações populacionais mais pobres da capital gaúcha, em sua grande maioria afrodescendentes, esse bairro se origina de uma política municipal na década de 1970, de transferência de famílias carentes para locais distantes do centro da cidade (Nunes, 1997).

Um dia após o noticiário, inicia-se uma mobilização pública articulada pela Rede Feminista de Saúde e suas entidades filiadas, apoiada pelo Conselho Municipal dos Direitos da Mulher, envolvendo o movimento de mulheres e movimentos sociais jovens, sindical, comunitário - para sensibilizar o Conselho Municipal de Saúde a tomar posição acerca dos fatos, informar a imprensa sobre os equívocos do programa e buscar aliados na sociedade através dos jornais locais, a iniciativa do movimento de mulheres teve resposta imediata do médico coordenador municipal do programa, que apresentava argumentos que se revelaram falaciosos com os esclarecimentos elaborados pelo Ministério da Saúde, como forma de desqualificação da oposição ao programa.

\footnotetext{
3 Restinga, Santa Cecília, Nossa Senhora das Graças, Glória, Rubem Berta, Belém Novo, Castelo, Panorama, Pequena Casa da Criança, Santa Marta e São Vicente, Modelo, Bom Jesus, Navegantes, Sarandi e Assis Brasil (dados extraídos do documento de convênio entre a Prefeitura e o IMC).
} 
A Rede Feminista de Saúde subsidiava o movimento de mulheres por meio de informações disponíveis no site do próprio Instituto Mulher Consciente - IMC, que noticiava o Projeto Adolescência - um projeto de vida, ${ }^{4}$ e também o convênio com a prefeitura. Entre os objetivos e finalidades, o site arrolava: “...II) promover e/ou participar de pesquisas clínicas, envolvendo seres humanos, de métodos profiláticos, diagnósticos e terapêuticos comprovados, tornando-os mais eficazes e eficientes..." (www.mulherconsciente.org.br) ${ }^{5}$. 0 estatuto reconhecia a necessidade de cumprir a legislação, normas e diretrizes dos conselhos municipal, estadual e federal de Saúde, assim como da Assistência Social e de Direitos da Criança e do Adolescente. O Laboratório Organon é apresentado como patrocinador enquanto o programa Parceiros Voluntários, vinculado à indústria Gerdau e à Federação das Indústrias do Rio Grande do Sul - FIERGS, como apoiador da proposta.

Atas e documentos em registros públicos e notas de imprensa subsidiaram a Nota Pública elaborada pela Rede Feminista, assinada por 14 entidades de mulheres ${ }^{6}$ e enviada para organismos nacionais e estaduais de governo, de controle social, de profissionais de saúde e poder legislativo ${ }^{7}$. Informações obtidas por meio de busca documental permitiram construir estratégias de resistência e de reversão do programa. A entidade Mulher Consciente havia sido criada há pouco tempo (abril de 2006), com o objetivo precípuo de desenvolver parceria com a Prefeitura e o programa já obtivera parecer favorável do Ministério Público no tocante à colocação dos implantes. Em julho do mesmo ano, a Fundação de Proteção Especial (ex-Febem) encaminhou pedido de autorização para uso de progesterona em bastões subdérmicos em adolescentes abrigadas. Soube-se também que a parceria com a Secretaria Municipal de Saúde (SMS), pactuada em agosto daquele ano, havia sido concebida no gabinete na Primeira Dama, sendo considerada uma ação prioritária. Além disso, o programa não fora submetido à análise do Conselho Municipal de Saúde e tampouco à Assessoria de Planejamento da SMS (instância que elabora as políticas municipais) e ao Comitê de Ética em Pesquisa. A ação municipal caracterizou-se pela celeridade: o anúncio do programa em mídia nacional deu-se poucos dias após a assinatura do convênio, em 26 de novembro de 2006.

Diante da inesperada ação do poder público, o movimento de mulheres saiu em busca de argumentos técnicos, políticos e bioéticos, enquanto o Conselho Municipal de Saúde passou a utilizar suas prerrogativas de definição das políticas públicas dirigidas a uma ação que já estava em curso.

Subsequentemente, a Nota-Denúncia "Implantes hormonais em jovens: a volta do controle da natalidade, uma violação aos direitos humanos", elaborada pela Rede Feminista e assinada pelos setores contrários ao programa municipal, deflagra um processo de mobilização local, nacional e internacional ${ }^{8}$, motivando encontros, debates e entrevistas para a definição de uma estratégia. 0 material proporcionou argumentos para a busca de aliados na sociedade e nas instâncias governamentais e do controle social.

Os meios de comunicação, por seu lado, posicionaram-se claramente em apoio ao programa. A partir de dezembro de 2006 até maio de 2007, o Conselho Municipal de Saúde conseguiu suspender tempo-

\footnotetext{
4 Este projeto, ora tratado como programa, ora como política, também tem várias denominações, sendo esta uma delas.

5 O site é retirado do ar no final de 2006.

6 Rede Nacional Feminista de Saúde, Direitos Sexuais e Direitos Reprodutivos - Secretaria Executiva e Regional do Rio Grande do Sul, Rede de Saúde das Mulheres Latino-Americanas e do Caribe - RSMLAC, Maria Mulher - Organização de Mulheres Negras, Coletivo Feminino Plural, Secretaria da Mulher da Federação dos Trabalhadores no Comércio do RS, União Brasileira de Mulheres, Mulheres Jovens Trocando Ideias, Conselho Municipal dos Direitos da Mulher de Porto Alegre, Themis - Assessoria Jurídica e Estudos de Gênero, Cátedra de Gênero - IPA Metodista, Cfemea - Centro Feminista de Assessoria.

7 Encaminhada para: Conselho Nacional de Saúde, Conselho Estadual de Saúde do RS, Conselho Municipal de Saúde Porto Alegre, Conselho Nacional dos Direitos da Mulher - CNDM, Conselho Nacional de Juventude, Conselho Nacional dos Direitos da Criança e do Adolescente CONANDA, Secretaria Especial de Políticas para a Mulher, Área Técnica de Saúde da Mulher do Ministério da Saúde, Secretaria Especial de Políticas de Igualdade Racial, Encontro Nacional da Articulação de Mulheres Brasileiras, Missão da Plataforma Dhesca no Brasil, Movimento Nacional dos Direitos Humanos, Febrasgo, Conselho Federal de Medicina.

8 A Rede de Saúde das Mulheres Latino-Americanas e do Caribe, com sede no Chile, desenvolveu uma ampla ação de divulgação do fato.
} 
rariamente o processo, com apoio do movimento de mulheres. Mas essas ações foram tratadas como "obstáculos" a uma iniciativa considerada positiva, uma vez que desde 2004 a gravidez na adolescência era um dos principais temas da campanha de conscientização em escolas, apoiada pelo Ministério Público Estadual. Em nível estadual, nos anos de 2004 e 2005, a primeira dama dedicou-se exclusivamente ao projeto “Te liga, gravidez tem hora!", com grande apoio da mídia. Enquanto sites de movimentos sociais de outros Estados brasileiros, e até do exterior, publicaram notícias com denúncias dos implantes com artigos, reportagens e entrevistas, alertando para os direitos reprodutivos, o movimento de mulheres articulava-se também com órgãos oficiais federais. Apontavam a necessidade de evitar a repetição de fatos que em décadas passadas haviam motivado a contenda que teve como palco principal no Brasil a CPI da Esterilização (1992) e, em nível internacional, a Conferência de População e Desenvolvimento do Cairo (1994).

Entidades mobilizadas pela Rede Feminista e suas filiadas, bem como entidades parceiras, além da participação de dezenas de movimentos populares em Porto Alegre e do Conselho Municipal dos Direitos da Mulher - COMDIM estabeleceram um desafio em torno de três questões principais: (1) como explicitar uma posição contrária à oferta de um único método contraceptivo, caro, acessível apenas às jovens de classes sociais abastadas, sem, de um lado, fortalecer posições moralistas contrárias ao uso de contraceptivos e à sexualidade entre adolescentes e jovens; (2) ao mesmo tempo, como defender o paradigma de direitos sexuais e reprodutivos?

O terceiro nível de questionamento referia-se ao papel do controle social das políticas de saúde, "flagrantemente burlado", segundo as participantes, no processo em tela. Teria o Conselho de Saúde os argumentos necessários para a defesa dos direitos sexuais e reprodutivos?

Tendo estas entidades definido o objetivo de reverter o quadro encontrado de forma a interromper o programa de implantes subdérmicos de hormônios em adolescentes de 15 a 18 anos de Porto Alegre, estabeleceu-se também como meta obter do poder público uma proposta de política de direitos sexuais e reprodutivos para o Município de Porto Alegre, baseada em pressupostos de autonomia e respeito às/aos adolescentes, fortalecendo o protagonismo do Conselho Municipal de Saúde em parceria com o movimento de mulheres.

Durante os seis meses em que a demanda pública se manteve (novembro de 2006 a maio de 2007) até a decisão final por parte do Conselho Municipal de Saúde, foi adotada uma estratégia argumentativa baseada na desmistificação dos dados sobre fecundidade das adolescentes de Porto Alegre. De um lado, tal estratégia articulou a defesa do acesso ao planejamento reprodutivo sob uma perspectiva de direitos humanos, sexuais e reprodutivos, baseada em instrumentos nacionais e internacionais e, de outro lado, a valorização do controle social e diálogo com os movimentos sociais como instâncias de onde o poder deve originar-se na democracia participativa, com a valorização do Conselho Municipal de Saúde.

Do ponto de vista político, o SUS, com qualidade como vetor de políticas de saúde equitativas e universais, constituiu a base de ação para elucidação de padrões técnicos e éticos de uso de contraceptivos, indicando os danos que as pesquisas e o uso inadequado de hormônios produziram em populações-alvo de testes. Outra ação consistiu na defesa de políticas públicas de saúde de qualidade, intersetoriais, a partir da Política Nacional de Direitos Sexuais e Reprodutivos e do Marco de Direitos Sexuais e Direitos Reprodutivos e Adolescentes do Ministério da Saúde. Por fim, a desvinculação de programas de entidades privadas de regulação de fertilidade, pelos riscos de uso mercadológico e para pesquisas com humanos.

Quanto ao Conselho de Saúde, suas ações voltaram-se para questionar o poder do município de firmar convênio com entidades privadas e recémcriadas para desenvolvimento de políticas e programas, como também para a autorização de ações com características de pesquisas em humanos, sem a aprovação do Comitê de Ética em Pesquisas em Saúde do Município. Além disso, questionou a distribuição de um insumo de saúde reprodutiva não preconizado pelas autoridades sanitárias federais, já que as Áreas Técnicas da Saúde da Mulher e da Saúde de Adolescentes do Ministério da Saúde pronunciaram-se pela suspensão das ações. Esse 
questionamento foi apoiado pelos Conselhos Nacional de Saúde e dos Direitos da Mulher, por entidades de direitos humanos nacionais e internacionais.

Uma agenda política é inaugurada na Câmara de Vereadores que, em audiências e seminário, solicita do Ministério Público, de um lado, esclarecimentos sobre seus pareceres e da Secretaria Municipal de Saúde, por outro lado, as justificativas para seus programas e políticas, determinando a elaboração de políticas no campo de saúde sexual e reprodutiva até então não elaboradas.

Após seis meses, quando finalmente o Conselho Municipal de Saúde obtém a suspensão do programa, a ONG recua e dissolve-se, é feita a redistribuição dos contraceptivos hormonais pela rede de saúde do município, de acordo com a Lei 9.263/96, do Planejamento Familiar.

Por fim, a Secretaria Municipal de Saúde apresenta à Câmara de Vereadores uma versão preliminar de Política Municipal de Saúde para Adolescentes, considerada um avanço em relação à prática anterior, em que pesem críticas recebidas do Conselho Municipal de Saúde e do movimento de mulheres, daí a ideia deste artigo considerar esse processo como parcialmente virtuoso em termos de resultado.

O mesmo não se pode afirmar em relação ao processo político como um todo, já que o diálogo entre a comunidade diretamente envolvida (a população do bairro da Restinga) e o movimento de mulheres teve essa relação mediada por agentes políticos municipais e foi realizada em seminários e audiências públicas, mas não in loco. Nessas oportunidades de encontro, evidenciou-se o uso de diferentes linguagens e compreensões sobre o significado de direitos reprodutivos, chamando-se a atenção, nos debates, a presença das mães das jovens que haviam recebido implantes, cujo discurso sobre gravidez na adolescência como um risco a ser evitado aproximava-se da argumentação da prefeitura e do Instituto Mulher Consciente.

$\mathrm{O}$ diálogo mais direto coube ao Conselho $\mathrm{Mu}-$ nicipal de Saúde, com representantes do bairro no Conselho Local de Saúde e algumas usuárias do "Programa", que ao sentirem-se prejudicadas na continuidade, acabaram por identificar o Conselho como aliado.
Presumivelmente, um debate mais amplo com essa comunidade poderia, por exemplo, ter evitado que o médico coordenador do programa obtivesse grande votação eleitoral na Restinga no pleito para vereador, ainda que o Conselho Municipal de Saúde tenha atuado na denúncia aos órgãos fiscalizadores.

Com esse desencadeamento inicial, encerra-se o que se considera como primeiro capítulo do caso dos implantes. A seguir, são apresentados os argumentos que ancoraram o discurso do movimento de mulheres e que foram oferecidos para integrantes do controle social.

\section{O Paradigma de Direitos Humanos e a Participação}

O conceito de direitos sexuais e reprodutivos como direitos humanos sucede o conjunto de políticas voltadas para as mulheres ao longo da história do Brasil, quando elas estiveram centradas no binômio mãe-bebê, portanto materno-infantil, atribuindo às mulheres a função central de reprodutoras. Desde a metade do século passado, estudiosas de todo o mundo têm questionado o destino imutável da maternidade como "missão sagrada", pois nem sempre significou a possibilidade de escolher entre várias opções, prevalecendo a ideia de um destino e, como tal, imutável (Greer, 1987; Beauvoir, 1967). Conceitos de saúde sexual e reprodutiva e seu tratamento como direitos são uma conquista muito recente, mas seus antecedentes históricos podem ser situados nos embates, nos séculos XVIII e XIX, entre Malthus e Condorcet sobre as políticas de fertilidade, inaugurando discussões que relacionam população e desenvolvimento (Correa e col., 20o6). Sob a crença de que a população cresceria em níveis muito acima das possibilidades de prover sua alimentação, trabalho e outros bens sociais, Malthus propunha a abstinência sexual e medidas coercitivas. Condorcet, por seu lado, possuía uma visão mais harmônica entre a possibilidade de crescimento populacional e desenvolvimento. Malthus deixou uma cultura política entre governantes, técnicos e filósofos, influenciando o pensamento político-demográfico até o final do século XX.

Até os anos 1990, com o objetivo de controlar os nascimentos e responsabilizar as famílias nume- 
rosas pela sua própria pobreza, políticas de caráter demográfico ancoradas na concepção (neo) malthusiana foram verificadas em países considerados subdesenvolvidos ou em desenvolvimento. Embora inúmeros autores considerem que o Estado brasileiro tenha optado pela neutralidade em relação às políticas de caráter demográfico, é certo que nas décadas do anos 1970 e 1980, instituições internacionais atuaram no Brasil, realizando esterilização de mulheres (Osis, 1998). A denúncia dessas práticas deu base a uma CPI no Congresso Nacional em 1992, antecedendo a Conferência de População e Desenvolvimento do Cairo, na qual novos conceitos foram escritos e pactuados.

A separação entre a sexualidade e a reprodução, bem como a desnaturalização do papel materno, tem seu momento-chave nos anos 1960 como reivindicação histórica das mulheres, quando se inicia a disseminação do uso das pílulas anticoncepcionais hormonais, descortinando novas possibilidades ao exercício da sexualidade. Uma nova experiência com a utilização de fármacos traz à luz questionamentos éticos e morais, pois das décadas de 1940 a 1970 registram-se inúmeras experiências com humanos em populações femininas do Caribe, América Central, América do Sul, Índia, África, entre outras (Greer, 1987), até hoje denunciadas e debatidas. Recente trabalho no campo da bioética (Diniz e col., 2008) coloca em discussão as pesquisas em saúde por estabelecer uma questão difícil de ser solucionada: até onde vai o benefício em relação ao tamanho do sacrifício das pessoas que integram as pesquisas e o custo que se propõem a pagar em nome de um possível ganho.

Levado ao extremo esse debate, Greer (1987) relata a aplicação de fármacos para teste de novos medicamentos em populações em situação de exclusão social, que sequer tinham condições de compreender os riscos aos quais estavam sendo expostas. Nos anos 1980, a falta de perspectiva de uma vida longa levou mulheres da Tailândia e Bangladesh ao uso de Depo-Provera injetável, atingindo elevados índices de aceitação entre as populações pobres. Essa aceitação foi assim analisada por Greer: "Primeiro, é uma injeção, com todos os fatores positivos atribuídos a um método de aplicação que todos testemunharam operar maravilhas. Segundo, não exige banheiro e não precisa ser guardado de rato e crianças. Não pode ser detectado, destruído ou removido por uma sogra, um marido ou qualquer outra pessoa" (1987, p. 173). A despeito dos riscos de a mulher morrer de câncer, ela acrescenta: "as suas chances de viver por tempo suficiente para morrer de câncer são escassas" ou, em termos mais brutais, ela gostaria do risco de morrer de câncer em vez de uma das doenças associadas à gravidez e parto" (idem). Já que o medicamento ainda estava em testes, a famosa autora descortina, assim, os frágeis limites entre integrar uma pesquisa e obter algum benefício ou não fazer parte e não ter outras possibilidades (Rogers e Ballantyne apud Diniz, 2008), um dilema que persiste nos dias atuais. Afirmação algo deslocada do tema deste artigo, mas não tão distante assim, como veremos.

Provavelmente o mais importante capítulo da história da saúde das mulheres brasileiras também tenha ocorrido na década de 1980 , no processo da reforma sanitária, que coincide com o final do regime autoritário no Brasil. Ao alterar o paradigma de atenção à saúde no Brasil e eleger a universalidade e a equidade como fundamentos, oportunizou-se o debate para uma nova concepção de saúde da mulher, tendo como princípio a integralidade (Costa, 2004). No coração desta política (o Programa de Assistência Integral à Saúde da Mulher, hoje Política Nacional de Atenção Integral à Saúde da Mulher), está o conceito de Planejamento Familiar. Polêmico à época e questionado pela Igreja de um lado, e visto com certa desconfiança pelo movimento de mulheres, de outro lado, em função do viés do controle demográfico demonstrado por algumas agências que atuaram no País nos anos 1970/8o (Osis, 1998), o programa trouxe o reconhecimento do direito de todas as pessoas de aceder às informações e meios que permitam planejar quando, como, em que circunstâncias e com quem ter ou não ter filhos. O PAISM, assim, se antecipa à Constituição de 1988, ao reconhecer este como um direito de todos os cidadãos e cidadãs no seu Art. 226, § $7^{\circ}$. Regulamentado pela Lei 9.263/1996, que define a responsabilidade do Estado, instituições de saúde e profissionais no que se refere à saúde reprodutiva, a Constituição coloca um ponto final para intenções que não sejam baseadas na livre opção das pessoas (Ventura, 2004). 
O Programa de Ação do Cairo/94 prevê um paradigma de direito reprodutivo no contexto da saúde sexual e reprodutiva. Também chamado de Consenso de Cairo, assinado por 179 países, resultou de disputa entre políticas populacionais stricto sensu para a defesa das premissas de direitos humanos, bemestar social e igualdade de gênero e do planejamento familiar para as questões da saúde e dos direitos sexuais e reprodutivos (Corrêa e col., 2004, p. 29).

Em seu Capítulo VII, o Programa do Cairo define a saúde reprodutiva como um estado geral de bemestar físico, mental e social e não mera ausência de doenças, em todos os aspectos relacionados com o sistema reprodutivo e suas funções e processos. Em consequência, a saúde reprodutiva envolve a capacidade de procriar e de desfrutar de uma vida sexual satisfatória e sem riscos, e a liberdade para decidir fazê-la ou não fazê-la, quando e com que frequência. Para assegurar essas possibilidades, está implícito o direito de homens e mulheres terem informações para planejar sua família e métodos de regulação de fertilidade que não estejam legalmente proibidos, bem como o acesso a métodos seguros, eficazes, acessíveis e aceitáveis, além do direito de receber serviços adequados de atenção à saúde que permitam gestações e partos sem risco e proporcionem aos casais as máximas possibilidades de ter filhos sãos.

Como definição de direitos reprodutivos, o Programa do Cairo chama a atenção tanto para a educação sexual, para que adolescentes e jovens possam assumir sua sexualidade de forma positiva e responsável, como para o combate dos preconceitos que levam a discriminações e atitudes negativas contra mulheres e meninas, e da sua limitação para poderem decidir sobre sua vida sexual e reprodutiva.

Apesar das críticas do movimento feminista endereçadas ao não reconhecimento dos direitos sexuais relativos à livre orientação sexual e à abordagem do tema do aborto apenas sob o aspecto da sua insegurança para as mulheres e nos limites das legislações nacionais, os 15 anos de vigência do Programa do Cairo ainda remetem aos direitos reprodutivos para decisão por "casais", embora a prática busque sua implementação por parte dos Estados signatários.

A Organização Mundial da Saúde, por sua vez, passa a adotar o conceito de saúde sexual e reprodutiva como um estado de completo bem-estar físico e psíquico, e não apenas a ausência de doença, e a possibilidade de viver a sexualidade e a reprodução na plenitude, com base na informação e acesso ao planejamento reprodutivo.

Assim, Cairo é um marco histórico para as mulheres, especialmente para o movimento feminista. Vistas anteriormente sob a ótica do controle da natalidade e dos corpos das mulheres, as questões demográficas foram gradativamente deslocadas para o âmbito dos direitos reprodutivos e do direito ao desenvolvimento (Ventura, 2004), incorporando o debate das décadas de 1980 e de 1990 e as resoluções das conferências conhecidas como o Ciclo Social das Nações Unidas, chegando aos anos 2000 com princípios de políticas públicas consolidados e baseados em direitos humanos (Correia e col., 2004).

A ideia de que todas as pessoas devem ter condições para exercer autonomia e para decidir sobre sua sexualidade e reprodução confere um novo patamar aos debates sobre as políticas de saúde. 0 movimento de mulheres transforma o PAISM em uma agenda permanente de reivindicação de um modelo de gestão em saúde no SUS que considere o paradigma da integralidade (Rede Feminista de Saúde, 2006).

As políticas nacionais de saúde da mulher passam a ser atualizadas a partir de 2002, com a elaboração de novas normas técnicas que configuram novo marco de saúde integral, de direitos sexuais e reprodutivos de adolescentes e mulheres ${ }^{9}$. A Política Nacional de Direitos Sexuais e Reprodutivos de 2004 preconiza que "A atenção integral à saúde da mulher compreende o atendimento à mulher $\mathrm{a}$

9 Norma Técnica dos Agravos à Saúde de Adolescentes e Mulheres Vítimas de Violência e a atual Prevenção e Tratamento dos Agravos resultantes da violência sexual contra mulheres e adolescentes; a Norma Técnica de Atenção Humanizada ao Abortamento; o Plano Nacional Integrado para Enfrentamento da Feminização da Epidemia do HIV e outras DSTs; a Anticoncepção de Emergência; a Política Nacional de Atenção Integral à Saúde da Mulher; o Controle dos Cânceres do Colo de Útero e da Mama; o Programa de Humanização no Pré-Natal e Nascimento (PHPN); o Pacto Nacional para a Redução da Mortalidade Materna e Neonatal, Programa Nacional de Planejamento Familiar, entre outros. 
partir de uma percepção ampliada de seu contexto de vida, do momento em que apresenta determinada demanda, assim como de sua singularidade e de suas condições enquanto sujeito capaz e responsável por suas escolhas" (Ministério da Saúde, 2004).

Hoje, as jovens e adolescentes alvos do Projeto de Implantes Hormonais de Porto Alegre seriam sujeitos de Proteção Integral com ganho de autonomia, conforme o Art. 17 do Estatuto da Criança e do Adolescente - Lei no 8.069, de 3/7/1990 que diz: “O direito ao respeito consiste na inviolabilidade da integridade física, psíquica e moral da criança e do adolescente, abrangendo a preservação da imagem, da identidade, da autonomia, dos valores, ideias e crenças, dos espaços e objetos pessoais (ECA).

Segundo o Marco Legal - Saúde, documento elaborado pelo Ministério da Saúde relativo a direitos dos adolescentes (2005), "Os direitos sexuais e os direitos reprodutivos se constituem de certos direitos humanos fundamentais já reconhecidos nas leis nacionais e internacionais, e nascem a partir da definição de saúde reprodutiva, buscando interagir os direitos sociais, principalmente, o direito à saúde, à educação, à informação, com os direitos individuais de não interferência e de não discriminação". E acrescenta: "Seus comandos centrais são: decidir livremente e responsavelmente sobre a própria vida, ter acesso à informação e ter acesso aos meios para o exercício dos direitos individuais livre de discriminação, coerção ou violência" (Ministério da Saúde, 2005).

Esse apanhado histórico apoiado em dados demográficos e epidemiológicos sobre Porto Alegre ajudou o movimento a refutar a tese oficial sobre a necessidade dos implantes hormonais como único método a ser ofertado para as populações de adolescentes em situação de vulnerabilidade naquele município. A argumentação em defesa de políticas integrais que ofereçam informação de qualidade, que possibilite escolha de atenção e de métodos mais adequados a cada pessoa também foi desenvolvida ao longo desse processo. Além disso, essa recuperação de informações também permitiu perceber a intenção velada de realizar pesquisa por meio do programa, intenção posteriormente explicitada por solicitação levada ao Comitê de Ética em Pesquisa, após a denúncia do programa, resultando em recusa.
Constatou-se que a capital gaúcha dispõe dos mais baixos coeficientes de natalidade do País 12,74\% (2006), mas considerável índice de gravidez na faixa de 10 e 19 anos (17,4\%), e taxas de abortamento acima da média nacional (correspondendo a cerca de $31 \%$ das gestações). Esse quadro é indicativo de falhas graves na política de saúde para a faixa etária de adolescentes, insinuando déficits de informação para o exercício da sexualidade, de educação sexual formal e informal. Por apontar baixo acesso aos métodos contraceptivos, à dupla segurança (um método mais o preservativo) baixo acesso à contracepção de emergência nos casos de dúvida quanto à eficácia do método utilizado sinalizar realização de abortamento clandestino e inseguro, essas informações apontam a complexidade do processo, implicando num conjunto de ações articuladas em saúde, educação, cultura e assistência.

Quanto à questão bioética, o movimento pautouse na denúncia de que a oferta única de implantes hormonais a toda a população de jovens exclusivamente selecionadas segundo a renda familiar, viola princípios orientadores do planejamento reprodutivo. Esses princípios referem-se à oferta de contraceptivos adequados a cada pessoa a partir de um conjunto de fatores analisados: ao uso de métodos conhecidos, seguros, adequados à idade; à não realização de qualquer tipo de pesquisa com humanos sem a devida aprovação de comitês de ética em pesquisa; e à certeza de que a escolha da população-alvo não se caracteriza por uma perspectiva racista ou discriminatória (Rede Feminista de Saúde, 2001).

Ciente, desde o início, de que se tratava de uma ação mediada e financiada por entidades privadas, coube ao movimento de mulheres exercer o controle social com base no acúmulo político e teórico da própria Rede Feminista. Aqui, a ação se processa em dois campos: o da ação comunicativa em saúde e incidência política, através do controle social das políticas públicas, e o campo da advocacy feminista em direitos sexuais e reprodutivos. Ainda que controle social e conselhos de saúde não sejam sinônimos e que se deva agregar documentos das conferências e dos próprios movimentos sociais, estas instâncias constituem importantes meios de sensibilização da sociedade em torno da saúde das 
mulheres, sendo necessário capacitar as próprias mulheres para atuar nesses espaços e realizar um constante trabalho junto a todos os conselheiros. Ademais, estudos sobre delegados de conferências mostram que as mulheres não só são minoritárias, como é menor o número daquelas advindas dos movimentos sociais quanto mais elevada a instância de controle (Ministério da Saúde, 2007).

No dizer de Almeida (2003, p. 180): "o controle social é um campo onde se exercem estratégias e atos essencialmente políticos - a negociação entre as partes para chegar a um resultado de consenso ou de unanimidade entre as partes que beneficie uma coletividade ou parte dela, o que constitui ação política de grande complexidade”. Tal ação implica em "ter sempre informações atualizadas e assertivas passíveis de ser confirmadas por dados fidedignos da realidade que, por sua vez, foram coletados e analisados por metodologias com credibilidade científica, além de conviver com a diversidade de interesses, de ideologias, de valores, de posturas democráticas e antidemocráticas". Para tanto, acrescenta, torna-se indispensável instrumentalizar-se, exercer domínio dos mecanismos e instrumentos políticos necessários ao sucesso e à obtenção dos resultados previstos, e exercitar os procedimentos de controle social (Almeida, 2003, p. 181).

Constitui um processo de fortalecimento das mulheres, seja através da existência de espaços participativos, de estímulos à participação e ao conhecimento, seja como ferramenta para seu empoderamento como sujeitos políticos, considerando o empoderamento como acesso das mulheres ao direito de participar do exercício do poder por meio de instituições formais, tais como estruturas governamentais, processos parlamentares e organizações não governamentais, objetivando a transformação social. Segundo autora sul-africana (Taylor, 1999), o empoderamento político ajuda a aumentar o poder e o controle das mulheres sobre suas próprias vidas, a exercer o direito a tratar das desigualdades estruturais e de assuntos sistêmicos e de ter influência e força coletiva dentro da sociedade para tomar decisões.

Taylor aponta três possibilidades para realizar esse processo: (1) por meio da ação direta dos movimentos de mulheres no embate pela construção de políticas públicas; (2) por meio de uma democracia de base na qual, através do diálogo, são superadas as contradições; e (3) por meio de uma cultura baseada nos direitos humanos, o que envolve a existência de mecanismos institucionais através dos quais as mulheres possam adquirir seus direitos ou, no mínimo, assegurar-se do direito a ter direitos (Negrão, 2006).

Enfrentar as questões sociais pelo engajamento da sociedade civil nas decisões políticas é requisito da democracia participativa não porque a participação em si resolva as profundas diferenças distributivas existentes, mas porque os baixos níveis de participação estão diretamente relacionados ao processo de exclusão de parte significativa da população. Assim é desencadeado o "círculo virtuoso" referido no início desta exposição (Figueiredo, 2001), segundo o qual o funcionamento regular dos Conselhos e a continuidade da participação da sociedade civil nessas instâncias e também nas conferências de saúde fomentam comunidades cívicas imbuídas de uma nova cultura, afinada com os valores da democracia substantiva. Apostar nessa relação informada e permanente em todo o processo em curso foi a proposta deste trabalho.

\section{Uma Incursão pela Restinga}

A pesquisa etnográfica no principal bairro em que o programa foi implementado foi motivada pelo debate público que se instalou a partir de novembro de 2006. Utilizando observação direta, entrevistas e análise de documentos, a referida dissertação de mestrado em Antropologia pela UFRGS² agregou uma dimensão que a intervenção política envolvida no movimento de mulheres e no conselho de saúde não conseguiu atingir.

Das 21 pessoas entrevistadas, 15 são mulheres com as quais a pesquisadora passou a conviver, acreditando que desvendaria nuances da realidade. Os resultados das entrevistas realizadas com mulheres de 13 a 27 anos que receberam a "tecnologia contraceptiva" revelam, de um lado, a distância entre o discurso biomédico e preventivo e a crença de que mais nascimentos significam mais problemas, mais crimes e trajetórias destruídas (discurso dos proponentes do programa de contraceptivos intradérmi- 
cos) e de que o sinônimo de sexo na adolescência é risco. De outro lado, indicam a confiança das jovens nesse discurso médico, confiança só abalada quando os implantes começam a produzir efeitos inesperados (inchaços e roxidões nos braços, ganho de peso, sangramentos, dores no corpo, perda da libido e até gravidez) ou quando percebem a falha da política pública na falta de acompanhamento médico, ou ainda quando o desejo de retirar o implante não é assegurado pelo posto de saúde.

O desconforto físico produzido pelo implante hormonal é atribuído à crença na força, na confiabilidade e eficácia do método que, apesar dos efeitos colaterais, apresenta uma fórmula de sucesso. 0 estudo mostra ainda que o campo de tomada de decisões das jovens-mulheres situa a disputa evidenciada nas entrevistas com gestores e com a primeira dama do município e, em especial, com a observação da postura do médico coordenador do programa (que possuía um projeto político-eleitoral). Pois, se de um lado o programa lhes aproximou a uma tecnologia cara e normalmente inacessível, de outro, o uso dessa tecnologia não significa uma mudança de rumo em suas vidas, na medida em que, de certa forma, suas trajetórias já estão traçadas. Ademais, o programa da prefeitura contempla a contracepção, mas não a reprodução. Portanto, é incompleto.

Suas reflexões remetem à questão: "de quem são estes projetos de não reprodução, principalmente quando se enfoca nas relações assimétricas de gênero e geração?" (Jardim, 2009, p. 115). Para essa autora, assim como outras, a tecnologia contraceptiva poderia ser utilizada pelas mulheres a partir de outras lógicas.

\section{Conclusões}

Este relato foi motivado pela experiência de militância na Rede Feminista de Saúde. Além dele, buscaram-se novos elementos nesta reflexão com aportes da Teoria Feminista e da perspectiva participacionista da Ciência Política e dos conceitos de direitos sexuais e reprodutivos que animam o movi- mento feminista nas últimas quatro décadas.

Quanto aos fatos descritos, estes ganharam a dimensão de uma agenda pública no sentido proposto por McCombs e Shaw em $1968^{10}$ ao colocarem em debate e disputa de argumentos a sociedade e seus diversos atores políticos, embora nem sempre em situação de igualdade, conforme se verifica na clara opção dos meios de comunicação pelas teses defendidas por um lado dos debatedores.

O paradigma dos direitos sexuais e reprodutivos adotado pelo Brasil para suas políticas públicas constitui um inegável avanço da sociedade, sua reafirmação, no entanto, é um exercício cotidiano dos movimentos sociais em relação ao Estado e às esferas de governo. 0 caráter da política pública que se tentou implementar em Porto Alegre, entre 2006 e 2007 evidencia essa dinâmica. 0 episódio conduziu a desmistificar dados demográficos e epidemiológicos e a que se demonstrasse que, ademais de não ser preconizado pelo Ministério da Saúde pelo alto custo e efeitos colaterais, a alegada eficácia do método contraceptivo de implantes hormonais contrariava o princípio de opção em torno de diversos métodos. A utilização de um único método em escala populacional é criticada pelas normas e legislação em vigor.

Quando adotados pelo Estado brasileiro, esses conceitos são interpretados de formas diversas conforme crenças de gestores ou de pessoas influentes, (como a primeira dama), ganhando outros significados para integrantes do Ministério Público e legitimando discursos e práticas sob questionamento. Através de parceria público-privada e com o respaldo dos meios de comunicação, a participação de empresas privadas e de uma ONG impôs um desafio de extrema dificuldade para a reversão de uma política pública equivocada. A compreensão dessa realidade levou o movimento de mulheres a reforçar a legitimidade do conselho de saúde como agente protagonista.

Sabe-se que controle social da saúde não se resume ao conselho de saúde, mas tem neste um elemento central, a depender do grau de democracia em

10 Segundo esses autores, "Enquanto as evidências de que os meios de comunicação mudam profundamente as atitudes em uma campanha está longe de ser conclusiva, a evidência mais forte é de que os eleitores aprendem com a imensa quantidade de informações disponíveis durante cada campanha" (Cf. McCombs; Shaw, 1972, p. 176)", in Lopez, 2009. 
cada nível de gestão. Por essa razão, o controle social deve vincular-se permanentemente aos movimentos sociais para fortalecer seu papel deliberativo, bem como reforçar a democracia participativa. Mesmo com esse histórico de lutas, sem a vigilância permanente por parte do controle social, conquistas importantes podem se perder ou se anular no curso de gestões. Somente uma relação sinérgica, que leve em conta interesses da população e respeite as instâncias democráticas, é capaz de reverter quadros complexos como o encontrado no final de 2006.

No caso em tela, cada instância teve sua contribuição, tendo como objetivo encontrar a melhor solução para o problema: reconheceu-se no conselho de saúde o papel de espaço-síntese da representação de interesses, não raro controversos, mas capaz de exercer uma representação de interesses das mulheres e adolescentes por sua composição majoritária de usuários. Essa interlocução envolveu outras instâncias democráticas, como os conselhos de direitos da mulher em nível estadual e municipal, ao mesmo tempo que se articulou com os meios de comunicação (mesmo os francamente favoráveis ao projeto em questão) para obter esclarecimentos, para debates e reportagens que inverteram o foco das notícias. A partir de então, optou-se pela valorização do saber técnico e pela ampliação da voz do gestor federal, responsável pela elaboração dos marcos técnicos do pedido. Com a emissão de Nota Técnica foi possível, de um lado, fortalecer a argumentação política do movimento de mulheres e do conselho de saúde e, de outro, fragilizar a tese dos defensores do programa. A valorização do corpo técnico municipal, por seu lado, retirou-o do isolamento anterior e devolveu-lhe o papel de elaborar e propor políticas calcadas em princípios da equidade e da universalidade, com parâmetros científicos e técnicos eticamente defensáveis.

Segundo avaliação realizada posteriormente pelo Conselho da Mulher, esse episódio simbolizou a necessidade de reafirmação da democracia participativa. Além disso, incorporou a comunidade no debate ao revitalizar o movimento de mulheres e valorizar o Conselho de Saúde em ações conjuntas pela difusão de parâmetros técnicos e bioéticos de política de saúde. Com o fortalecimento do capital social sinérgico, desencadeia-se um círculo virtuoso do processo, fruto do reconhecimento dos diversos atores e atrizes envolvidas, da confiança estabelecida e da reciprocidade entre aliados, configurando uma experiência que gerou novos aprendizados.

Ao valorizar as alianças e o diálogo com a sociedade, os avanços abriram caminho para mudanças, ainda que não se tenha alcançado uma política pública calcada não só no acesso universal e na equidade, como no pressuposto da autonomia dos sujeitos e sua diversidade. Essa uma experiência que o movimento feminista vem realizando nas últimas décadas no Brasil, que se enriquece quando feita em parceria e aliança com outros movimentos sociais.

\section{Ecos do Processo}

O Caso dos Implantes Hormonais de Porto Alegre não se deu por encerrado em maio de 2007. O Conselho Municipal de Saúde manteve a vigilância e o controle sobre a distribuição dos insumos contraceptivos, verificando-se, através de Relatório de Gestão de 2008, com dados de 2007, que a Gerência Distrital da Restinga continuou colocando os implantes - dos 1963 inseridos em pacientes entre 2006 e 2007, 910 foram na região, onde se manteve o mesmo ritmo de colocação. Também o Conselho foi procurado por jovens que não haviam obtido sucesso na tentativa de retirar os "implantes", sendo necessário acionar o Ministério Público para a busca de atendimento.

O tema se mantém como uma agenda importante no Legislativo Municipal. Em 2008 foi criado por Lei um Centro Municipal de Planejamento Familiar, que vem sendo questionado quanto à sua constitucionalidade, funcionando precariamente num hospital municipal. Outro projeto do vereador-médico pretende estender o programa de implantes para mulheres no sistema prisional, mas a proposta foi rejeitada pelo departamento de saúde prisional do Estado. Enfim, uma história que não acabou.

\section{Referências}

BEAUVOIR, S. O segundo sexo - a experiência vivida. São Paulo: Difusão Européia do Livro, 1967. v. 2. 
BRASIL. Ministério da Saúde. Marco Legal saúde, um direito dos adolescentes. Brasília, DF, 2005. Disponível em: <http://portal.saude.gov.br/ portal/arquivos/pdf/marco_legal.pdf >. Acesso em: 11 maio 2012.

BRASIL. Ministério da Saúde. Política Nacional de Atenção Integral à Saúde da Mulher. Princípios e Diretrizes. Brasília, DF, 2004.

COELHO, C. C. Acesso, qualidade e humanização na assistência farmacêutica com controle social. Artigo. Disponível em: <http://conselho.saude.gov. br/biblioteca/Relatorios/confer_nacional_de\%20 medicamentos.pdf >. Acesso em: 10 jul. 2008.

CORREA, S. et al. Dez anos do Cairo: tendências da fecundidade e de direitos reprodutivos no Brasil. Campinas, SP: Abep, Brasília, DF: Unfpa, 2004.

CORRÊA, S. et al. Direitos e saúde sexual e reprodutiva: marco técnico-conceitual e sistema de indicadores. In: CAVEGNAGHI, S. (Org.). Indicadores municipais de saúde sexual e reprodutiva. Rio de Janeiro: Abep, Brasília, DF: Unfpa, jul. de 2006.

COSTA, A. M. Atenção integral à saúde das mulheres: QUO VADIS? Uma avaliação da integralidade na atenção à saúde das mulheres no Brasil. Tese (Doutorado em Medicina). 2004 Universidade de Brasília, Brasília.

DINIZ. D. et al. Ética em pesquisa: temas globais. Brasília, DF, Editora UNB, 2008. p. 9-24, 123-52.

FIGUEIREDO, J. E. S. Comunidade cívica, capital social e Conselhos de Saúde no Estado do Rio de Janeiro. Dissertação (Mestrado em Saúde Pública). 2001 - Escola Nacional de Saúde Pública, Fundação Oswaldo Cruz, Rio de Janeiro.

GREER, G. Sexo e destino - a política da fertilidade humana. 2. ed. Rio de Janeiro: Rocco, 1987.
JARDIM, R. T. O controle da reprodução: estudo etnográfico da prática contraceptiva de implantes subcutâneos na cidade de Porto Alegre/RS. 2009. Dissertação (Mestrado em Antropologia Social) Universidade Federal do Rio Grande do Sul, Porto Alegre, 2009.

LOPEZ, D.C. Agenda setting e enquadramento. Algumas considerações sobre os estudos de efeitos dos meios de comunicação. Revista PJ:Br - Jornalismo Brasileiro, São Paulo, n.11, fev. 2009. Disponível em: <http://www.eca.usp.br/pjbr/ arquivos/artigos11_a.htm>. Acesso em: 25 out. 2009.

NEGRÃO, T. Ciberespaço, via de empoderamento de gênero e formação de capital social. 2006. Dissertação (Mestrado em Ciência Política). ) Universidade Federal do Rio Grande do Sul, Porto Alegre.

NUNES, M. K. Restinga. In: Memória dos bairros de Porto Alegre. Secretaria Municipal de Cultura, 1997.

REDE FEMINISTA DE SAÚDE. Adolescentes: saúde sexual saúde reprodutiva. Dossiê. MG, 2004. REDE FEMINISTA DE SAÚDE. Saúde da mulhere direitos reprodutivos. Dossiê. São Paulo, 2001.

REDE FEMINISTA DE SAÚDE. Nota-denúncia implantes hormonais em jovens: a volta do controle da natalidade, uma violação aos direitos humanos. Porto Alegre, 10/12/2006.

TAYLOR, V. Reestructura política y transformación social. Perspectiva feminista. In: Memoria del Seminario Internacional Reestructura Política y Trasformación Social. Dawn/Repem. Uruguai, 1999, p. 9-28.

VENTURA, M. Direitos reprodutivos no Brasil. Fundo de Populações das Nações Unidas. Brasília/ DF, 2004. 